\title{
O PROFISSIONAL RE-CONHECENDO A FAMÍLIA COMO SUPORTE SOCIAL PARA A PRÁTICA DO ALEITAMENTO MATERNO
}

\author{
THE HEALTH PROFESSIONAL RECOGNIZING FAMILY \\ AS SOCIAL SUPPORT FOR THE PRACTICE OF BREAST FEEDING \\ ELPROFESIONAL DE SALUD QUE RECONOCE A FAMILIA \\ COMO AYUDA SOCIAL PARA LA PRÁCTICA DELAMAMANTAMIENTO
}

Isilia Aparecida Silva*

\begin{abstract}
RESUMO: Estudo realizado com profissionais da saúde que trabalham diretamente com mães e bebês em amamentação, demonstrou que embora estes embasem sua prática na crença de que amamentar é natural, estes mesmos profissionais compreendem que há inúmeros determinantes do curso da amamentação originados do contexto materno. Um dos elementos identificados nesse contexto é a influência, positiva ou negativa, que a família exerce sobre a nutriz. Dessa forma um novo modelo assistencial deve contemplar a aproximação maior do profissional com a nutriz e sua família, no intuito de ter nesta a possibilidade de construir um suporte para criar melhores condições para mulher e família vivenciarem o processo de amamentar como uma experiência prazerosa para todos os atores sociais nela envolvidos.
\end{abstract}

DESCRITORES: Aleitamento materno; Família; Ocupações em saúde.

\section{AMAMENTAÇÃO COMO OBJ ETO SOCIAL}

À amamentação, enquanto prática social, tem-se atribuído inúmeros papéis no amplo campo da promoção da saúde materno-infantil.

Considerada como uma das estratégias fundamentais para a garantia de um estado nutricional e condições de desenvolvimento de excelência para a criança, implicando também, na redução da ocorrência das doenças infantis, em especial para os lactentes, o incremento do ato de amamentar, tem sido efetivamente, um dos principais temas nas agendas das políticas públicas de saúde materno-infantil, de investimentos em campanhas de promoção voltada à população em geral e, em transformações de modelos assistenciais para mãe e lactente. Também tem sido importante objeto de investigação científica na área da saúde, nas últimas três décadas, em especial a partir dos anos 80 .

A diminuição dos índices de interrupção da amamentação de crianças antes dos primeiros seis meses de vida, tornou-se, desde o final da década de 70 , uma das principais metas de programas que tratam da saúde infantil no Brasil e em muitos países ocidentais, com apoio e incentivo da Organização Mundial da Saúde e Organizações Não Governamentais (Silva, 1999).

A partir dos programas específicos de promoção, incentivo e apoio ao aleitamento materno e, mesmo os que atuam indiretamente no sentido de promover a prática da amamentação, têm sido criadas e implantadas inúmeras estratégias e alternativas que têm resultado em sucesso na conquista pela construção cultural de propiciar condições para a prática de amamentar para mulheres de nossa sociedade (Boletim ..., 1994).

É sabido que muitos são os fatores interferentes na decisão da mulher em amamentar. Essa prática não está na dependência única de sentimentos instintivos ou, de conhecimentos adquiridos sobre técnicas de amamentação ou vantagens sobre o leite humano e amamentação.

Por muito tempo, as ações relativas a promoção, apoio e incentivo ao aleitamento materno foram fundamentadas nos conceitos de educação da população e dos profissionais sobre os aspectos técnicos básicos

* Enfermeira, Professora Associada do Departamento Enfermagem Materno-infantil e Psiquiátrica da Escola de Enfermagem da USP 
da amamentação e atributos do leite materno na promoção da saúde infantil. Partia-se do pressuposto de que se poderia re-criar a cultura da amamentação ensinando mulheres a amamentar e, treinando profissionais, substituindo rotinas antigas, consideradas prejudiciais para a prática da amamentação para alcançar as metas de promoção, incentivo e apoio ao aleitamento materno (Silva, 1996).

Nesse sentido, as campanhas, as ações programáticas envolvendo educação e treinamento, reformulação de práticas profissionais e de serviços, tiveram como meta, atingir a mulher que amamenta ou que potencialmente seria nutriz.

As belas figuras, pinturas, gravuras e inúmeras imagens que tentaram retratar a maternidade em sua força criadora e mantenedora da raça humana, tiveram na expressão de ternura e pureza das faces de bebês mamando em peitos anônimos, o estabelecimento da relação direta de mama e lactente, conclamando as mães a demonstrarem o amor pelos seus filhos através do ato de amamentar.

No entanto, mesmo que tenhamos tido muito sucesso a cerca de 20 anos, avançarmos no aprimoramento de muitas estratégias para promover a amamentação, ainda hoje, temos muitos "nós por desatar" uma vez que, em grande parte do país os índices de amamentação exclusiva, em média, não ultrapassam 34 dias, sendo que em algumas cidades do Sudeste a média de aleitamento está por volta de 17 dias (Marques, 2000).

Uma questão a ser discutida no modelo assistencial vigente, é a falta de apoio às mulheres no momento em que elas mais precisam de cuidados e acolhimento para resoluções de intercorrências da lactação/ amamentação na continuidade ao aleitamento. Quando a mulher encontra profissionais capazes de atuar de forma a identificar junto a ela sua necessidade e oferecer resolutividade no momento preciso, dificilmente esta deixa de amamentar (Silva, 1998; Machado, 1999).

Amamentação é um conjunto complexo de ações resultantes de um processo estimativo e avaliativo, vivenciado pela mulher que amamenta, no decorrer de sua experiência concreta de amamentar. Um processo cognitivo/emocional que envolve os conhecimentos e habilidades maternas sobre ações de amamentação mas, também envolve as suas percepções acerca dos sentimentos provocados pela experiência de amamentar, confrontados com suas expectativas, perspectivas de vida, contexto profissional, convivências familiares, ou seja, toda sorte de interações da mulher e o entorno que a envolvem e a seu filho (Silva, 1997).

$\mathrm{Na}$ obra acima citada, percebe-se a influência sobre as decisões maternas em relação a amamentação, exercida por profissionais, seja na forma autoritária com que julgam ordenar para as mães aleitarem seus filhos e, que nada garante que isso aconteça, ou nas orientações equivocadas que muitas vezes confundem e validam padrões culturais errôneos acerca de mitos sobre a incapacidade de mães produzirem leite para seus filhos. Em qualquer uma das situações, os profissionais pouco têm conseguido interagir eficientemente com as mulheres bem como, promover o aleitamento além dos muros hospitalares ou influenciar na manutenção e aumento do tempo de duração. Uma vez em seu ambiente natural, longe da fiscalização dos profissionais e seus padrões proibitivos, as mulheres tomam suas decisões, muitas vezes sofrendo outros tipos de influências, talvez não menos negativas ou estressantes, sendo que muitas vezes essas se originam na família.

A força exercida pela opinião dos profissionais sobre a expectativa de performance da nutriz é, muitas vezes, equivalente as pressões que ela recebe em seu ambiente familiar.

As mulheres, em geral vivem o conflito de ter que atender as normas sociais que designam o processo de amamentar como uma ação inerente de sua condição de mãe. E m seu ambiente, a mulher vivencia diversas situações contraditórias de avaliação e julgamento de sua performance lactacional por seus familiares, em que as opiniões advindas do companheiro, mãe e sogra em geral, têm um forte peso na avaliação e estimativa de sua experiência e capacidade de amamentar (Silva, 1997).

\section{FALANDO DE PROFISSIONAIS E DE FAMÍLIAS NO PROCESSO DE AMAMENTAÇÃO}

Assim, o significado que a mulher atribui a sua experiência de amamentar é elemento nuclear no processo de decisão e na qualidade da experiência dessa prática vivenciada por ela. Da mesma forma, consideramos que os profissionais também constróem a assistência em amamentação com base nos significados que atribuem ao processo de amamentar e as suas ações assistenciais.

Para tanto desenvolvemos um estudo que visou compreender a estrutura da assistência prestada por pediatras, obstetras e enfermeiras que lidam diretamente com mães e lactentes em amamentação, do Município 
de São Paulo, tendo como objetivo, identificar os símbolos significantes que fazem parte da construção da assistência em amamentação e os elementos de interação presentes na vivência do profissional em assistir a mulher e a criança em amamentação, em consultórios próprios ou que trabalhassem diretamente com nutrizes em instituições hospitalares públicas com sistema de alojamento conjunto (Silva, 1999).

Os depoimentos desses profissionais, colhidos através de entrevistas informais, foram analisados tendo como referencial os pressupostos teórico e metodológico, o Interacionismo Simbólico a Teoria Fundamentada nos Dados, respectivamente.

Nesse estudo, constatou-se que os profissionais têm como forte elemento na construção de sua assistência a crença de que "amamentar é um ato natural" valorizando aspectos biológicos e sociais da amamentação, já consagrados na sociedade e literatura científica, reificados pelos bancos acadêmicos.

0 fenômeno central do estudo em questão, constituiu-se na expressão significativa da crença do profissional que amamentar é natural. Sendo assim, representa um processo alicerçado no instinto materno e nas obrigações sociais que a mulher deve assumir ao tornar-se mãe e prover ao filho o carinho, proteção, condições de sobrevivência e desenvolvimento adequados, através da amamentação.

Entre os inúmeros conceitos emergidos nesse estudo que compõe a experiência do profissional, chamanos a atenção, que uma das principais categorias, diz respeito aos aspectos interacionais da dinâmica familiar da nutriz, como algo que transcende a natureza imposta ao aleitamento materno e que se configura em elemento de atenção por parte do profissional.

Assim, no evoluir de sua experiência com mulheres em fase de amamentação, o profissional observa que muitas das decisões maternas são regidas por elementos subjetivos, interpretados por ele como interferentes no curso da amamentação. Esta descoberta resulta em um exercício de compreensão sobre a amamentação, que o faz perceber esta prática como uma experiência complexa, determinada também, por elementos que estão além do determinismo biológico da lactação.

0 profissional percebe que muitas de suas dificuldades em promover a amamentação, estão associadas às condições do contexto familiar e social da mulher, e que influenciam o curso da experiência de amamentar.

Esse pensamento representa a percepção de que a amamentação é construída por uma diversidade de experiências da mulher na interação com seu filho e com elementos de seu contexto. Nesse sentido, 0 profissional sente-se descobrindo alguns desses elementos, na busca de compor o quadro geral sobre a amamentação.

Embora o recorte biológico seja a visão prioritária em que o profissional baliza sua crença sobre a importância da prática da amamentação, ao reconhecer componentes da subjetividade da experiência da mulher, como fatores que podem interferir no curso da amamentação, ele acaba re-conhecendo a mulher como agente da amamentação, o que significa que o profissional toma conhecimento da força das concepções próprias da mulher nas decisões quanto ao amamentar. Nessa perspectiva, há o reconhecimento de que muitos aspectos, envolvidos nesta prática, são inerentes à experiência materna e, assim, na medida que o profissional toma contato com a mulher no exercício da assistência em amamentação, ele vai enxergando a subjetividade da experiência da mulher em amamentar.

"Eu acho que a gente não tem idéia da dimensão da coisa (da amamentação).Deve ter muita coisa envolvida que a gente não chega nem na metade".

Pensar por este prisma desencadeia a sensação no profissional de que muitas atitudes maternas não são compreendidas por estas serem fruto de aspectos aos quais ele não se vê em condições de alcançar.

"Não sei por que acontece (o desmame). No caso desta paciente que eu te falei, ela era uma paciente tão preparada, com tudo dando certinho e de repente vem falando que não deu certo, que a criança não quis mais. Eu não sei se foi mesmo isso..."

No curso desse pensamento, o profissional vai percebendo que a mulher toma as decisões sobre a amamentação, ou seja, de que a mulher, ao decidir-se por amamentar ou não, baseia-se em seus próprios conceitos sobre essa prática e seu papel de nutriz, conceitos estes, a que o profissional atribui à influência do contexto em que ela vive e à bagagem cultural que ela tem. 
Nessa perspectiva o profissional acredita que a visão das mulheres sobre o amamentar, é construída em experiências de amamentação vivenciadas por ela própria ou captadas em seu contato social com outras mulheres, bem como aquelas experiências que fazem parte do repertório familiar, que o profissional interpreta, como potencialmente positivas ou negativas.

Re-conhecer na mulher, como determinante desse processo, não só sua vontade de amamentar, mas uma força composta pela subjetividade de sua experiência, orienta o profissional para a observação do contexto em que ela vive, significa que o profissional se vê re-conhecendo outros elementos da amamentação. Esse exercício resulta na identificação de elementos do cotidiano da mulher e de seu filho e que diz respeito à influência do ambiente familiar, do grupo social, das interações internas da mulher, que ocorrem sob influência das pressões sociais e familiares a que ela está sujeita.

Tomar contato com esses elementos, sentir a limitação de sua atuação frente a fatores integrados à vida da mulher, significa para o profissional um exercício de ampliação da sua visão acerca das dimensões que compõem o processo de amamentar, mobilizada a partir das situações que ele identifica e classifica como obstáculo ao incentivo e, conseqüentemente, à realização da amamentação.

À um primeiro conjunto de elementos contextuais interferentes na amamentação, ele denomina de enxergando influências do contexto familiar, o que significa que o profissional identifica em sua prática fatos ou situações, determinantes do processo da amamentação e que têm sua origem no contexto e interação familiar da nutriz.

A família é assim percebida, pelo profissional, tendo uma participação ativa, sendo também fonte de pressões sobre a nutriz. Mesmo que em algumas situações a família não tenha contato direto com o profissional, este percebe e, interpreta, através do discurso materno, que a família é responsável por mensagens contraditórias e ambíguas, dirigidas às mulheres, quanto ao curso da amamentação e que são veiculadas à medida que a condição de fome e demais condições de bem-estar da criança são consideradas satisfatórias ou não.

“Ela (nutriz) está em um estado extremamente confuso, com uma criança que ela não sabe se está a limentando direito ou não, toda deprimida (...) e, tem às vezes uma mãe que insiste que ela amamente quando ela morre de dor, porque está tudo fissurado, e às vezes num primeiro choro mais contínuo da criança, essa mesma mãe diz: dá uma mamadeira agora. “

Dessa maneira, o profissional interpreta a vivência da nutriz como uma experiência sob inúmeras pressões, em que ela é responsabilizada pela nutrição da criança, está insegura, sofrendo desconfortos, sendo muitas vezes, influenciada pelas instruções familiares, que flutuam conforme a interpretação das manifestações de comportamento da criança, e que nem sempre estão em consenso com as orientações dadas pelos profissionais.

Assim, a família é simbolizada pelo profissional como um manancial de ajuda ou de "atrapalhação" nas ações de incentivo ao aleitamento materno.

Outro conjunto de elementos, é identificado a partir das referências da nutriz, como a dor provocada pelas intercorrências da lactação e amamentação, o cansaço decorrente da irregularidade no sono e da demanda contínua da criança para a amamentação que, segundo os profissionais são fatores que explicam o desgaste físico das nutrizes.

Assim, percebendo a sobrecarga física a que a nutriz está exposta, diz respeito a interpretação que o profissional faz desse conjunto de elementos como obstáculos potenciais para a amamentação, sendo vistos por ele como influentes na decisão materna, induzindo a interrupção do aleitamento materno, tanto pela dificuldade materna em conciliar a atividade de amamentar com repouso para recuperação de suas energias, como pela interferência fisiológica que esses elementos trazem, resultados na diminuição da quantidade de produção de leite, o que se constitui, em indicador para a introdução de outros alimentos.

"A mãe sente dor, fica cansada. A amamentação é um fator muito estressante para a mulher. Muitas vezes isso é o que conta para ela..."

Além do desgaste físico, o profissional também vai percebendo o desgaste emocional representado por elementos originados por pressões familiares, inexperiência da nutriz em avaliar o choro persistente do recémnascido e de suas diversas manifestações, a incerteza de que a criança está sendo alimentada adequadamente, 
a falta de orientação sobre aspectos práticos e técnicos da amamentação. Estes fatos são interpretados pelo profissional, como elementos de exacerbação de ansiedade materna pelo fato da mãe concentrar sua preocupação na saciedade da fome do recém-nascido.

"A mulher acaba sendo muito cobrada, né? A gente percebe que a preocupação é com o alimento, se o nenê tá passando fome. Também quando a criança chora é a primeira coisa que as pessoas falam: Mãe o nenê tá com fome!"

$\mathrm{Na}$ concepção do profissional, ao contrário de outros cuidados prestados ao recém-nascido, como banho e troca de fraldas, amamentar é uma atividade que depende da mãe, ninguém pode fazer por ela, por essa razão é foco freqüente de ansiedade materna, podendo prejudicar o curso da amamentação.

"A mãe é muito solicitada, só ela pode amamentar. Os outros cuidados alguém pode fazer, se ela tiver quem faça, mas amamentar é com ela."

Assim, a família é percebida como um locus onde a mulher deveria ser poupada evitando-se o desgaste físico e emocional, mas nem sempre os familiares estão em condições ou sabem dar acolhimento para as necessidades da mulher. Segundo Silva (1997), as nutrizes estão sempre sofrendo influências de seu contexto, em especial a família representa tanto o suporte para a superação de dificuldades, como muitas vezes, a partir de seu repertório social, induz ao desmame por crenças e experiências vividas em outros processos de amamentação.

0 profissional também percebe, na dinâmica familiar, os sentimentos que influem na maneira como a mulher vivencia a amamentação e que são provocados a partir da relação conjugal e que ele denomina de influências na sexualidade e auto-imagem, quando consegue, identifica dificuldades enfrentadas e manifestadas por elas em conciliar a amamentação com as atividades sexuais.

"Elas ficam muito constrangidas vendo o leite sair na relação e o marido fica todo incomodado...tem homem que tem nojo...".

Percebe também, a insegurança de uma nova gravidez, quando reiniciam as atividades sexuais mantendo a amamentação.

"Elas ficam super preocupadas de amamentar e poder engravidar de novo, elas querem se sentir seguras...em geral vão pro obstetra e pedem um anticoncepcional".

Ou ainda, a insatisfação da mulher com relação ao seu corpo, a drenagem constante de leite, que a leva a tomar medidas para restabelecimento de sua auto-imagem.

"...é muito comum, nessas situações, a mulher optar pelo desmame, e a gente não tem muita alternativa".

As questões relativas à conciliação da amamentação e o retorno às atividades sexuais, segundo Silva (1997), constituem-se em um dos principais indicadores para a opção materna de interrupção da amamentação. Seu desejo ou necessidade de atender ao seu papel conjugal, provoca alto nível de ansiedade, em especial para mulheres que não desejam ou temem uma nova gravidez.

Assim, o profissional dá indicações de sua compreensão sobre o processo de amamentação. Mesmo considerando que a amamentação é um processo natural, as diversas experiências e formas distintas com que as mulheres agem em relação à amamentação, levando a refletir sobre as necessidades das nutrizes para conseguirem dar continuidade à amamentação.

Face a compreensão da experiência materna, o profissional se vê Tendo que dar suporte à mulher, 0 que se configura em um dos elementos da assistência em amamentação direcionada para a transformação da prática no sentido de ofertar suporte à mulher na gestação e período pós-natal. Isso significa a ampliação do período temporal da assistência e a consideração dos elementos contextuais da vivência da mulher em amamentar.

Em conseqüência, tendo que estar ao lado da mulher, é a maneira como o profissional considera possível oferecer o suporte necessário para que ela tenha sucesso na amamentação. É também, a forma como ele interpreta ser possível estabelecer vínculos e ganhar a confiança da nutriz, ampliando suas relações de trabalho com a mesma desde o pré-natal e por toda a fase da amamentação. 
"Eu acredito que é preciso fazer um trabalho de continuidade, estar junto com ela desde o pré-natal, orientando, preparando, e depois fazer visita no puerpério, visita domiciliária. Assim acho que é possível se fazer uma boa assistência em amamentação e incentivar que ela aconteça."

Nesse sentido, o profissional passa a considerar que a assistência não pode ser desvinculada do contexto familiar e social em que a mulher está inserida e, para que os objetivos do trabalho de incentivo, promoção e apoio ao aleitamento materno possam ser alcançados, o profissional se vê tendo que valorizar a família, como resultado de sua percepção sobre as influências que a família exerce sobre a nutriz. 0 profissional busca assim, valorizar o papel da família junto a mãe e filho, aliando-se aos familiares para obter melhor resultado na assistência em amamentação.

“...é preciso valorizar os vínculos com a família para atingir os objetivos que a gente tem de melhorar a amamentação".

A valorização de pessoas significativas para a nutriz, significa a criação de uma aliança que permite envolvimento e parceria entre profissional e família, em que todos contribuem com seus conhecimentos e potencialidades, para um bem comum. 0 profissional interpreta o papel da família como um complemento do suporte, não apenas técnico mas, social que a mulher necessita para exercer a prática de amamentar.

“...o envolvimento do marido é fundamental, ele é um reforço muito positivo quando ele apoia a amamentação...".

“...quando a família está tranqüila e confiante, a mãe tem ajuda e tranquilidade para amamentar...".

Dessa maneira, quando o profissional considera a importância dos elementos interacionais do contexto materno, como interferentes no processo de amamentar e na qualidade dessa experiência para a nutriz, ele se dispõe a partilhar seu saber com a família e formar uma rede social que dê suporte à mulher para superar dificuldades e vivenciar a amamentação, ou o desmame, com melhor qualidade.

\section{A FAMÍLIA COMO OBJ ETO DE ATENÇÃO}

Face a sua prática, pautada na crença de que amamentar é natural, o profissional é desafiado por razões que não consegue compreender, diante das atitudes de mulheres, em relação à amamentação, que contrariam o pensamento de que amamentar é natural. A limitação de sua compreensão e ação frente a estas situações, o conduz ao exercício de compreensão sobre as ações maternas e resultam na identificação de elementos da subjetividade da experiência feminina em amamentar.

A descoberta de que a amamentação, também é determinada por objetos sociais do contexto da mulher, passa a ser uma nova crença adquirida pelo profissional, não necessariamente decodificada e incorporada em sua prática, o que significa uma compreensão não totalizada da experiência da mulher. Reconhecer os elementos contextuais da mulher e seus dados de subjetividade, como interferentes na amamentação, além do curso biológico, o conduz à percepção da necessidade da re-orientação da prática, uma vez que o profissional passa a atribuir à mulher as decisões sobre o curso da amamentação, colocando-a como agente deste processo.

Re-orientar suas ações incluindo a vontade da mulher como objeto a ser considerado no conjunto da assistência, demanda a interação entre profissional e nutriz em um nível de parceria e cumplicidade, que exige dele disponibilidade afetiva e investimento pessoal para o exercício dessa nova modalidade de prática. Esses atributos se mostram condicionados às diferenças pessoais do profissional reforçadas ou construídas a partir de suas vivências com a prática da amamentação.

Somados a esses fatos, o profissional apresenta um dado novo, incorporando a família como elemento do contexto da nutriz, capazes de interferir positiva ou negativamente nesse processo e, portanto, indicando a necessidade do profissional interagir não apenas com a nutriz, mas aproximar-se ao máximo do ambiente materno, trazendo para junto de si os familiares como aliados no objetivo de dar condições à mulher para amamentar.

Nesse sentido, é possível considerar que os familiares estão sendo vistos como componentes do contexto da dupla mãe e filho e não como pessoas, que também necessitam de apoio e de suporte para superação de suas necessidades frente ao processo de nascimento de um novo membro da família. 
Assim como, a família tem sido considerada como objeto de cuidados nas situações de doença que acomete um de seus membros, também necessita, muitas vezes, da presença, compreensão e intervenção profissional nas situações do processo de vida, em ocorrência dos eventos ditos "naturais", segundo a fase de vida de seus entes.

Cabe aqui, dessa forma, a discussão do fenômeno relacional entre profissionais e clientela, no contexto temporal do nascimento de uma criança e, o processo de aleitamento materno, que é vivenciado, não apenas pela mãe e filho, mas por muitos dos familiares, em especial os mais próximos da nutriz. A família tem maneiras próprias de cuidar e transmitir seus significados em relação aos processos de vida, que estão relacionadas ao seu contexto sócio-cultural, cabendo ao profissional a compreensão de suas ações e significados para desenvolver ações coerentes e que façam sentido com seus objetivos assistenciais e a vivência de sua clientela e, não apenas como pessoas a mais que cumprirão com as determinações do profissional segundo as normas estabelecidas por este (Leininger, 1991; Elsen, 1984).

Da mesma forma que estes são percebidos pelos profissionais como interferentes no processo de tomada de decisão materna, pelas inúmeras possibilidades interacionais em qualidade e significados, é preciso expandir nossos propósitos de interagir com a família no sentido de buscar não apenas aliados para o sucesso da amamentação, mas também acolhê-lhos em suas dúvidas e inseguranças acerca desse processo, que muitas vezes são as origens das interferências negativas nas decisões maternas quanto ao rumo da amamentação, exigindo do profissional a sensibilidade de compreender e apreciar "a complexidade interacional da vida familiar" face ao processo de amamentação de um novo membro da família (Angelo, 1999,p.9).

FIGURA 1 - O profissional re-conhecendo a família como suporte social.

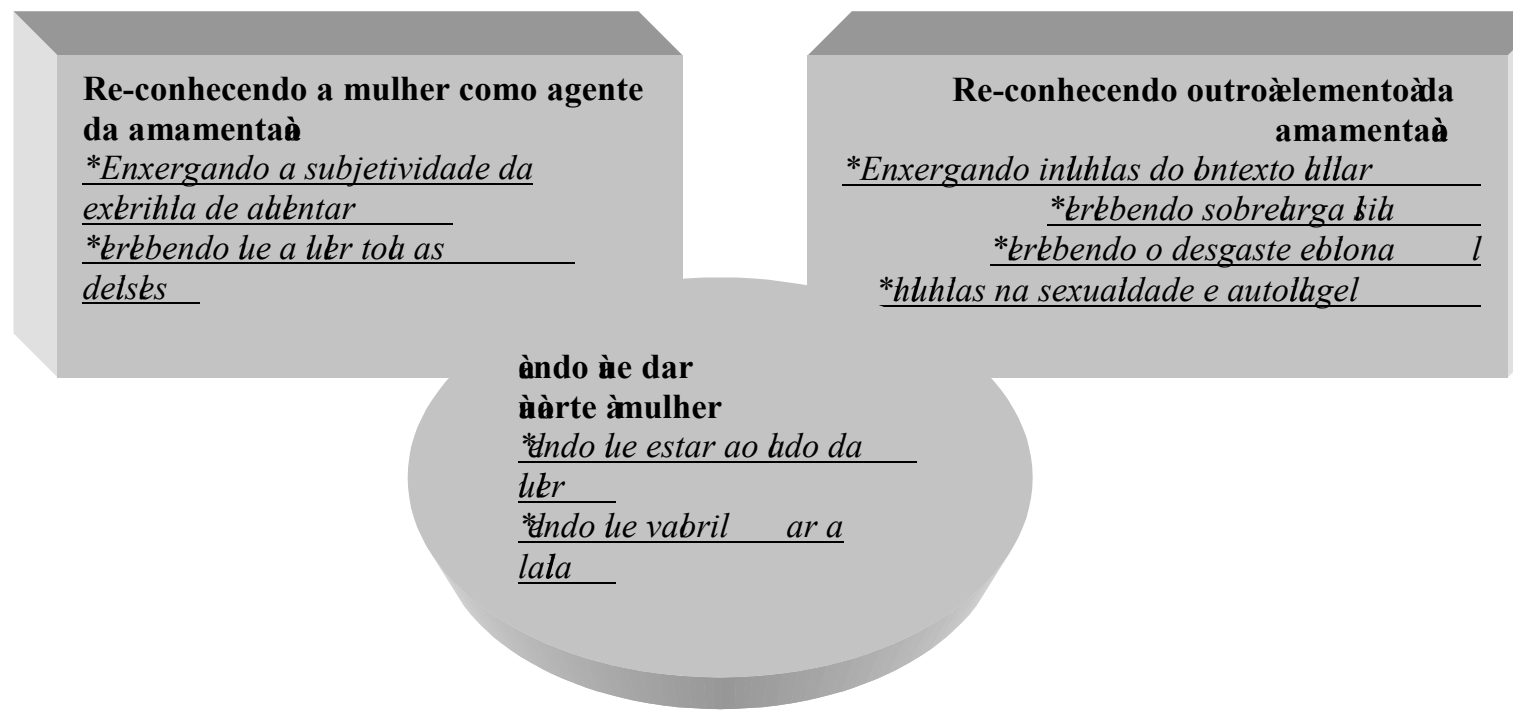

ABSTRACT: This study was carried out with health professionals who work directly with mothers and babies in breastfeeding. It showed that, although they base their practice on the belief that breastfeeding is natural these same professionals understand there are any number of determining factors around breastfeeding which come from the mother's setting. One of the elements identified in this context is the influence, whether positive or negative, which the family has over the mother. A new care model should seek to bring the health professional closer to the mother and her family, so as to make it possible to build support to create conditions for the woman and her family to live through the breastfeeding process as a pleasurable experience for all those involved.

KEY WORDS: Breastfeeding; Family; Health occupations.

RESUMEN: Esto estudio fue realizado con profesionales de salud que trabajan directamente con las madres y los bebés en amamantación. Mostró que, aunque basan su práctica en la creencia que amamantar es 
natural, estos mismos profesionales entiendem que hay inúmeros determinantes de la amamantacion cuál viene de lo contexto materno. Uno de los elementos identificados en este contexto es la influencia, si el positivo o la negativa, que la familia ejerce sobre la madre. Un nuevo modelo del cuidado debe intentar traer al profesional de salud más cercano a la madre y a su familia, para permitir construir la ayuda para crear las condiciones para que la mujer y su familia vivan con el proceso de amamantar como una experiencia agradable para todos ellos implicados.

PALABRAS CLAVES: Lactancia materna; Família; Empleos en salud.

\section{REFERÊNCIAS}

1 ANGELO, M. Abrir-se para a família: superando desafios. Fam. Saúde Desenv., v.1,n.1/2, p.7-14, jan./dez. 1999.

2 BOLETIM INICIATIVA HOSPITAL AMIGO DA CRIANÇA, Brasília, dez. 93/jan.94, 1994.

3 ELSEN, I. Concepts of health and illness and related behaviour among families living a Brasilian fishing village. San Francisco: UCSF, 1984. 301p. Tese (Doutorado- Ciências da Enfermagem) - University of California.

4 LEININGER,M. Culture care diversity and universality: a theory of nursing. New York: National league for Nursing, 1991.

5 MACHADO, M.M.T. A conquista da amamentação: o olhar da mulher. Fortaleza, 1999. p. 165.Dissertação (Mestrado) Departamento de Enfermagem, Universidade Federal do Ceará.

6 MARQUES, J. Brasileiras amamentam por apenas 34 dias. Folha de São Paulo.[on line]. Disponível:<http:// www.uol.com.Br/fs/cotidian/ff201020002 h.t.m. Acesso em: 20 out. 2000.

7 SILVA, I.A. Construindo perspectivas sobre a assistência em amamentação: um processo interacional. São Paulo, 1999. 145p. Tese (Livre Docência) - Escola de Enfermagem, Universidade de São Paulo.

8 SILVA, I. A. Amamentar: uma questão de assumir riscos ou garantir benefícios. São Paulo: Robe, 1997.

9 SILVA, I. A. Reflexões sobre a prática do aleitamento materno. Rev. Esc. Enf. USP. v.30, n.1. p.58-72, 1996.

10 SILVA, I.A. Enfermagem e aleitamento materno: combinando as práticas seculares. In: CONGRESSO BRASILEIRO DE ENFER MAGEM, 50, Salvador, 1998. Resumos. Salvador, ABEn-Seção-Ba, 1998, p.64. 